\title{
PARCERIAS PÚBLICO-PRIVADAS NO CONTEXTO EDUCACIONAL: A EXPANSÃO EM DISCUSS ÃO
}

\author{
PUBLIC-PRIVATE PARTNERSHIPS IN THE EDUCATIONAL \\ CONTEXT: EXPANSION IN DISCUSSION
}

\section{PARCERIAS DEL PÚBLICO Y PRIVADA EN EL CONTEXTO EDUCACIONAL: EXPANSIÓN EN DISCUSIÓN}

\begin{abstract}
Cristiane Rêgo dos Anjos ${ }^{1}$
Rede Municipal de Ensino de Teresina, Professora; Universidade Federal do Piauí, Pesquisadora do Núcleo de Estudos Pesquisa e Extensão em Políticas e Gestão da Educação; Bolsista da Coordenação de Aperfeiçoamento de Pessoal de Nível Superior (Capes)

\section{Rosana Evangelista da $\mathrm{Cruz}^{2}$}

Universidade Federal do Piauí, Professora do Programa de Pós-graduação em Educação, Coordenadora do Núcleo de Estudos e Pesquisas em Política e Gestão da Educação
\end{abstract}

Resumo: No estudo objetivou-se discutir sobre a expansão das parcerias públicoprivadas na educação, enfocando as estabelecidas entre a Secretaria Municipal de Educação de Teresina, PI, e as Organizações da Sociedade Civil. A discussão parte da reconfiguração da gestão da educação pública no Brasil decorrente da reforma do Estado, em diálogo com autores como Ball e Youdell (2008), Adrião et al. (2009), entre outros. O percurso metodológico da pesquisa compreendeu uma abordagem qualitativa e análise documental. Os resultados mostraram que as parcerias público-privadas na educação estão em processo de expansão e fortalecimento, bem como sinalizam uma tendência de privatização exógena da educação, com a inserção das políticas de ensino privadas na educação pública municipal.

Palavras-chave: Política educacional. Público e privado. Privatização da educação.

Abstract: The study aims to discuss the expansion of public-private partnerships in education, focusing on the links established between the Municipal Department of

\footnotetext{
${ }^{1}$ Pós-graduada em Docência na Educação Infantil pela Universidade Federal do Piauí; Graduada em Pedagogia pela Universidade Estadual do Piauí; mestranda em Educação pela Universidade Federal do Piauí.

${ }^{2}$ Doutora e Mestre em Educação pela Universidade de São Paulo.
} 
Education in Teresina, PI, and civil society organizations for the provision of education policies. The discussion begins with the reconfiguration of management of public education in Brazil, resulting from the State reform, in dialogue with authors such as Ball and Youdell (2008), Adrião et al. (2009), among others. The methodological course of the research comprised a qualitative approach and documentary analysis. The results showed that public-private partnerships in education are in a process of expansion and strengthening, as well as signaling a trend towards exogenous privatization of education, with the insertion of private education policies in municipal public education.

Keywords: Educational policy. Public and private. Privatization of education.

Resumen: El estudio tiene como objetivo discutir la expansión de las parcerias pública-privadas en la educación, centrándose en los que se establece entre la Secretaría Municipal de Educación de Teresina, PI, y las Organizaciones para la oferta de las políticas de enseñanza. La discusión parte de la reconfiguración de la gestión de la educación pública en Brasil, decurrente de la reforma del Estado en diálogo con autores como Ball y Youdell (2008), Adrião et al. (2009), entre otros. La ruta metodológica de investigación incluyó un abordaje cualitativo y análisis documental. Los resultados muestraram que parcerias pública-privadas en la educación estão en un proceso de expansión y fortalecimiento, así como señalizan una tendencia de privatización exógena de la educación, con la inclusión de las políticas de enseñanza privada en la educación pública municipal.

Palabras clave: Política educativa. Público y privado. La privatización de la educación.

\section{INTRODUÇÃO}

A abertura do espaço educacional público para a implantação de políticas do setor privado se constitui como prática em expansão, efetivada a partir de parcerias entre as secretarias de educação públicas e organizações de iniciativa privada, principalmente desde as reformas introduzidas no País nos anos 1990.

Paralelo a esse avanço, cresce o número de pesquisadores que se propõem a discutir o significado e as consequências dessa relação, entre os quais se podem citar Adrião et al. (2009), Adrião e Peroni (2005), Gentili (1999), Ball e Youdell (2008), entre outros.

Para os referidos autores, as parcerias são um mecanismo de expansão do capital, visto que a inserção de políticas pensadas pelo setor privado para as redes 
de ensino públicas resulta em tendências de privatização da educação e, sobretudo, assegura o controle sobre os processos educativos para a garantia dos interesses de mercado.

Contrários a essa concepção, teóricos como Mello (1993) e Oliveira (2006) afirmam que as parcerias para a oferta educacional fazem parte de um novo projeto de sociedade e atendem às reais necessidades brasileiras, como: formar capital humano competitivo e apto a enfrentar os problemas da modernidade e fomentar o desenvolvimento econômico do País para o fortalecimento de sua participação no mercado concorrencial mundial.

Para Ball e Youdell (2008), é necessário desnudar as influências dessas medidas, a fim de refletir sobre os efeitos dessas parcerias para o campo educacional. Nesse sentido, uma pesquisa internacional realizada pelos referidos autores, em 2008, mostra que o setor privado, enquanto parceiro do setor público, interfere na gestão e/ou organização de políticas educacionais gerando, assim, tendências de privatização da educação, as quais se classificam, respectivamente, em endógenas e exógenas. Pontualmente, a privatização endógena corresponde à efetivação de políticas de caráter mercadológico pelos próprios gestores públicos, como a promoção interna de ranqueamento e a bonificação docente. A privatização exógena refere-se à abertura de serviços educacionais públicos à participação do setor privado para a organização do ensino.

Em algumas cidades brasileiras, a privatização de caráter exógeno apresenta-se de forma mais expressiva. É o que mostram os resultados da pesquisa de Adrião et al. (2009), realizada em 645 municípios paulistanos. Em síntese, além de explicitar a crescente expansão das parcerias, a investigação revela a abertura do campo educacional público para a atuação privada, por meio da identificação do protagonismo do setor privado na elaboração e definição de políticas educacionais públicas para os municípios investigados, as quais se efetivam por intermédio da compra de sistemas apostilados de ensino e/ou adoção de "tecnologias" ou assessorias privadas para a organização da gestão das secretarias de educação.

A exemplo dos municípios paulistanos supracitados, ocorre expressiva expansão de parcerias e incorporação de políticas educacionais privadas na cidade de Teresina, PI. Nesse âmbito, o objetivo com o presente artigo é discutir a ampliação da parceria público-privada no campo da educação, sublinhando, especificamente, a Secretaria Municipal de Educação (Semec) de Teresina, PI, mediante o mapeamento dos conveniamentos entre a referida rede e as Organizações da Sociedade Civil (OSC), além de caracterizar as parcerias e o seu processo de fortalecimento para a gestão de 
políticas municipais, a partir da compra de sistemas apostilados de ensino para a Educação Infantil e o Ensino Fundamental.

A pesquisa é importante por fomentar o debate e a reflexão sobre as influências das parcerias na gestão de políticas públicas educacionais. Assim, para a sua realização, o recorte temporal compreendeu os anos 2001 a 2016, período de expressiva expansão de políticas privadas, no âmbito da Semec. Posteriormente, enfocou-se a relação que a referida Secretaria estabelece, desde o ano 2003, com o Instituto Alfa e Beto (IAB).

É relevante pontuar que a investigação se realizou a partir da análise documental (LAKATOS; MARCONI, 2016) em materiais como: notícias postadas no site da Semec (2001-2016), Diários Oficiais do Município (DOM) de Teresina, PI, (20032016) e informações do site do IAB.

O escopo do artigo compreende, inicialmente, a discussão a partir das bases teóricas que fundamentam a gênese e os interesses que asseguram a parceria público-privada para a organização de uma parcela significativa das políticas educacionais brasileiras. Posteriormente, aborda-se a expansão da relação público-privada, explicitando a incidência de parcerias em âmbito nacional e no Município de Teresina. Em seguida, promove-se uma discussão mais específica sobre o conveniamento entre a Secretaria em questão e o IAB, concomitante com a descrição de sua constituição e a caracterização de seu processo de fortalecimento dentro da Rede Municipal de Ensino. Por fim, realiza-se uma síntese da análise, na perspectiva de explicitar as conclusões finais sobre a temática em estudo.

\section{BASES TEÓRICAS DA RELAÇÃO PÚBLICO-PRIVADA PARA A OFERTA DAS POLÍTICAS PÚBLICAS}

As atuais parcerias público-privadas para a educação ocorrem em um contexto objetivo de organização econômica da sociedade, ou seja, no modo de produção capitalista. O capitalismo consiste em um modo de produção voltado para a acumulação e a expansão do capital. Sua gênese data imediatamente após a queda do sistema feudal, e, ao longo do tempo, apresentou diversas fases, como: comercial (séc. XVI-XVIII), em que o acúmulo de riqueza vinha do comércio de matérias-primas não existentes na Europa; industrial e/ou concorrencial (séc. XVIII-XIX), na qual o acúmulo de riqueza era proveniente da industrialização europeia; monopolista e/ou financeira (séc. XX aos dias atuais), que se caracteriza pelo crescimento acelerado e pela concentração de riqueza (SILVA, 2007). 
Embora a constituição do capitalismo tenha emergido da desestruturação da sociedade feudal, o fluxo do capital intensificou-se na segunda metade do século XVIII, com a Primeira Revolução Industrial, tornando-se fator determinante para a ascensão desse sistema.

Para Mészáros (2011), o capital é anterior e, também, sucessor do capitalismo, considerando que este é apenas uma das formas de realização do capital. Nessa dinâmica estrutural, o objetivo principal é garantir a expansão e a acumulação, o que perpassa por instabilidades e crises profundas ao longo do tempo.

Essas crises estão intimamente ligadas à constituição das diferentes fases do capitalismo, as quais são resultantes da expressão ativa do setor produtivo na tentativa de expansão, como informa Harvey (2011, p. 7):

\begin{abstract}
O capital é o sangue que flui através do corpo político de todas as sociedades que chamamos de capitalistas, espalhando-se, às vezes como um filete e outras vezes como uma inundação, em cada canto e recanto do mundo habitado. É graças a esse fluxo que nós, que vivemos no capitalismo, adquirimos nosso pão de cada dia, assim como nossas casas, carros, telefones celulares, camisas, sapatos e todos os outros bens necessários para garantir nossa vida no dia a dia. A riqueza a partir da qual muitos dos serviços que nos apoiam, entretêm, educam, ressuscitam ou purificam é criada por meio desses fluxos. Ao tributar esse fluxo, os Estados aumentam seu poder, sua força militar e sua capacidade de assegurar um padrão de vida adequado a seus cidadãos. Se interrompemos, retardamos ou, pior, suspendemos o fluxo, deparamo-nos com uma crise do capitalismo em que o cotidiano não pode mais continuar no estilo a que estamos acostumados.
\end{abstract}

Compreendendo o sistema capitalista como instável a partir do ritmo do seu fluxo de capital, Harvey (2011) explicita o fator central para a manutenção e/ou crise do sistema em discussão. Para o autor, as crises são inerentes ao sistema e têm uma estreita ligação com a superacumulação, podendo a crise ser de caráter local e curta ou mundial, profunda e duradoura.

Ressaltando a crise imobiliária dos Estados Unidos, em 2008, Harvey (2011) aduz que ela não é um fato isolado, possuindo suas raízes na condução da crise mundial dos anos 1970, qualificada por Mészáros (2011, p. 18, grifo nosso) como crise estrutural. Para esse autor, 
[...] o capital assume cada vez mais a forma de uma crise endêmica, como um depressed continuum, como uma crise cumulativa, crônica e permanente, com a perspectiva de uma "crise estrutural cada vez mais profunda", ao contrário da sua conformação anterior, cíclica, que alternava fases de desenvolvimento produtivo com momentos de "tempestade".

A crise estrutural dos anos 1970, ainda em vigência, emergiu a partir do desequilíbrio econômico mundial, intitulado de crise fiscal pelos defensores do neoliberalismo, por considerarem que a instabilidade financeira surgiu do período de predomínio do Welfare State. ${ }^{3}$

Especificamente, os neoliberais argumentavam que o excessivo protecionismo social estatal era prejudicial para a manutenção do capital. Logo, ganhou força o projeto ideológico mundial embasado pelo pensamento neoliberal, como uma alternativa constituída por estratégias políticas, econômicas e jurídicas orientadas para encontrar uma saída dominante para a referida crise (GENTILI, 1999).

O neoliberalismo, como doutrina econômico-filosófica, nasceu no contexto do pós-Segunda Guerra Mundial e, consoante Draibe (1993), atravessou diferentes fases. Inicialmente, a proposta de superação da crise econômica do Estado se sustentava na visão radical influenciada pela teoria liberal de Milton Friedman, que negava a social democracia enquanto promotora de políticas sociais, defendendo a necessidade de minimização do Estado. Na segunda fase, as concepções neoliberais foram incorporadas em políticas justificadas pelo crescimento da globalização e eclosão de novas tecnologias. Posteriormente, a partir dos anos 1990, a mutação dos ideais neoliberais estava arraigada no processo de modernização e de crescimento da competitividade, fato que impactou em reformas estruturais e sociais, vislumbrando uma integração internacional e o desenvolvimento sustentado.

É no contexto dessa última fase que as reformas pautadas no ideário neoliberal dos anos 1990 são implantadas em grande parte das nações mundiais, particularmente nos países de Terceiro Mundo. Na América Latina, conforme Batista (2001), a sua expansão possui como marco inicial as determinações da reunião realizada na cidade de Washington, nos Estados Unidos, em 1989, com representantes dos governos conservadores, representantes das instituições financeiras internacionais sediadas nos EUA - como o Banco Mundial (BM), o Fundo Monetário Internacional

\footnotetext{
${ }^{3}$ Segundo Offe (1984), o Welfare State e/ou Estado de bem-estar social é uma forma de organização política e econômica na qual o Estado assume a função de provedor das políticas sociais, bem como de organizador da economia. Compartilhando da lógica da decisão política econômica keynesiana, suas origens ideológicas são consideradas heterogêneas indo desde fontes socialistas até fontes católicas conservadoras.
} 
(FMI) e o Banco Internacional de Desenvolvimento (BID) -, além de economistas latino-americanos dos governos das economias em desenvolvimento.

O objetivo central do encontro foi realizar a avaliação econômica dos países latino-americanos em desenvolvimento que implantaram reformas recomendadas por agências internacionais, com exceção do Brasil e Peru, pois não participaram da primeira etapa desse processo reformista. A reunião demonstrou saldo positivo aos propositores das reformas, culminado em um conjunto de 10 medidas para os anos posteriores, reunidas no documento nomeado Consenso de Washington, ${ }^{4}$ cujas diretrizes são: disciplina fiscal, priorização dos gastos públicos, reforma tributária, liberalização financeira, regime cambial, liberalização comercial, investimento direto estrangeiro, privatização, desregulação e propriedade intelectual (BATISTA, 2001).

A implantação dessas medidas pelos países em desenvolvimento asseguraria a manutenção do crédito financeiro, deixando, assim, as nações sem escolha quanto à sua efetivação, dadas as condicionalidades impostas nos acordos de cooperação internacional. A incorporação das propostas reformistas, nesse contexto, apresentou-se como uma moeda de troca entre os países do Terceiro Mundo e as grandes potências mundiais, explicitando, nas entrelinhas, que a desigualdade também é mantida em âmbito global para que a expansão ideológica se efetive sem contestações.

No Brasil, a manifestação dessas medidas de cunho neoliberal iniciou-se no Governo de Fernando Collor de Mello, do Partido Trabalhista Brasileiro (19901992), com a abertura do mercado brasileiro e, consequentemente, a sua subordinação ao capital financeiro mundial globalizado. Mesmo após o seu impeachment, essa prática manteve-se na gestão de seu sucessor, representante do Partido Social Democrata Brasileiro (PSDB), Itamar Franco (1993-1994), e efetivou-se organicamente com a reforma estatal nos anos 1990, no Governo de Fernando Henrique Cardoso, também do PSDB (1995-1998; 1999-2002), influenciando diretamente a gestão das políticas sociais, entre elas, a educacional (LIBÂNEO; OLIVEIRA; TOSCHI, 2012).

A supracitada reforma brasileira foi materializada no documento intitulado O Plano Diretor de Reforma do Aparelho do Estado (PDRAE), construído na gestão de Fernando Henrique Cardoso (FHC), sob a administração de Carlos Bresser Pereira, até então responsável pelo Ministério da Administração Federal e Reforma do Estado (Mare), nos seguintes termos:

A reforma do Estado deve ser entendida dentro do contexto da redefinição do papel do Estado, que deixa de ser o responsá-

\footnotetext{
${ }^{4}$ Para mais detalhes sobre o Consenso de Washington, consultar Batista (2001) e Kuczynski e Williamson (2004).
} 
vel direto pelo desenvolvimento econômico e social pela via da produção de bens e serviços, para fortalecer-se na função de promotor e regulador desse desenvolvimento. (BRASIL, 1995, p. 12).

Assim, a partir da Reforma, o Estado brasileiro seria reestruturado em quatro setores: o núcleo estratégico, em que são definidas as leis e políticas públicas; as atividades exclusivas do Estado, que representam aquelas relacionadas ao poder de legislar e tributar; os serviços não exclusivos e competitivos, que, embora não envolvam o poder de Estado, são realizados ou subsidiados por ele por serem considerados de alta relevância para os direitos humanos; e a produção de bens e serviços para a sociedade, realizada pelo Estado, por meio das empresas de economia mista que operam em setores (PEREIRA; SPINK, 1997).

Entre os serviços não exclusivos do Estado, o Mare incluiu as escolas, as universidades, os centros de pesquisa científica e tecnológica, as creches, os ambulatórios, os hospitais, as entidades de assistência aos carentes, entre outros.

Para Pereira e Spink (1997), não seria viável considerar as instituições educativas como atividade exclusiva da esfera pública, pois isso dificultaria a garantia educacional; para os autores, o seu caráter competitivo permitiria que essa atividade fosse controlada por intermédio da administração pública gerencial e, ainda, por meio do controle social ou Terceiro Setor. Fazem parte do Terceiro Setor as Organizações da Sociedade Civil (OSC), que compreendem as Organizações não governamentais (ONGs), fundações, institutos, entidades beneficentes (filantrópicas), entidades sem fins lucrativos (associação de bairros, faculdades e escolas) e doadores (empresas privadas, pessoas físicas e outros) (PEREIRA; SPINK, 1997).

No contexto brasileiro, a Reforma Estatal reconfigurou o papel do Estado na promoção de políticas sociais, em um intenso movimento de descentralização, que deu sustentáculo ao surgimento das chamadas parcerias envolvendo a esfera privada e as OSC na promoção de políticas sociais, mediante a criação de vários mecanismos jurídicos. Entre as regulamentações jurídico-políticas que asseguraram a relação público-privada, encontram-se a Lei do Voluntariado, n. 9.608/98, a Lei das Organizações Sociais, n. 9.637/98 e a Lei das Organizações da Sociedade Civil de Interesse Público do Terceiro Setor, n. 9.790/99. Segundo Luz (2009, p. 79), as regulamentações descritas foram "todas sancionadas com o intuito de definição dos atores, dos espaços intermediários de sua atuação e das formas de sua participação nas políticas sociais."

De acordo com Peroni (2013), a descentralização é uma proposta para a organização estrutural do Estado, apresentada pelo PDRAE, a fim de efetivar o seu 
papel de regulador diante da oferta de políticas sociais, por meio da passagem dessa responsabilidade aos estados e municípios. Assim, para a eficiência e eficácia dos serviços, agregou-se ao processo de descentralização a proposta de modelos gerenciais de administração pública, partindo dos seguintes princípios: orientação para o cidadão-cliente, controle por resultados e competição administrada (BRASIL, 1995). Nessas circunstâncias, o conceito de direito é substituído pelo de serviço, e o de cidadão, por cliente, resultado da participação do setor privado na gestão de políticas públicas.

O contexto mais amplo de transformações implica ajustes nas políticas educacionais brasileiras, que passam a prever uma participação minimalista estatal, com o processo de descentralização, concomitante com a abertura do espaço de gestão da coisa pública ao Terceiro Setor, expandindo, assim, a inserção da lógica mercadológica no âmbito da gestão de políticas educacionais, considerando o fomento ao capital humano. Para Peroni (2013), essa visão de educação baseada na produção de capital humano converge com a neoliberalização da educação (prática da teoria neoliberal), a qual tem o mercado como o regulador do bem-estar social, por meio da promoção da competitividade e da naturalização da ascensão social como resultado da luta individual.

Consoante Libâneo, Oliveira e Toschi (2012), os referidos ajustes resultaram da incorporação da agenda internacional de Educação para Todos (EPT), organizada a partir de reuniões entre agentes financeiros multilaterais, entre eles, o Banco Mundial. Essas orientações são implementadas, no contexto nacional, pelo Ministério da Educação, em parceria com as OSC, por meio de políticas enfocando questões como o financiamento da educação, formação de professores, currículo, avaliação e gestão, bem como o incentivo às parcerias para implantação dessas medidas, em âmbito estadual e municipal. Nesse sentido, a reforma da educação é fruto de interesses que transcendem o território nacional e se estabelecem em favor da reestruturação do capital, a partir de uma agenda global para o desenvolvimento.

Para Ball e Youdell (2008), o incentivo à parceria tem provocado um processo de privatização no campo educacional público, seguindo duas tendências classificadas como endógenas e exógenas que, respectivamente, explicitam-se por meio da efetivação de políticas internas mercadológicas, como ranqueamento e bonificação, e por meio da abertura do campo educacional público para a implantação de políticas privadas de ensino, por diferentes meios, como a compra de sistemas apostilados, por exemplo.

Os sistemas de ensino são programas idealizados por empresas ou organizações da iniciativa privada que ofertam pacotes educacionais contendo materiais 
didáticos e assessorias externas para redes educacionais, as quais interferem no currículo, na formação docente, na avaliação e na gestão do ensino (ADRIÃO et al., 2009). É importante destacar, consoante Ball e Youdell (2008), que esse investimento estatal em políticas privadas de ensino torna o setor público uma fonte de lucro do setor privado.

É inescusável frisar que essa prática ainda permanece arraigada nas gestões posteriores a de Fernando Henrique Cardoso, representadas por Luiz Inácio Lula da Silva (2003-2006; 2007-2010) e Dilma Rousseff (2011-2014; 2015-2016), mediante a conservação e a ampliação de propostas de reformas no campo das políticas educacionais, como o Programa de Financiamento Estudantil (Fies) e a criação do Programa Nacional de Acesso ao Ensino Técnico e Emprego (Pronatec), bem como das novas regulamentações jurídicas de fomento às estratégias neoliberais de privatização e publicização, respectivamente por meio da criação da Lei n. 11.079/04, que institui a Parceria Público-Privada (PPP), e da recente reestruturação e substituição da antiga Lei do Terceiro Setor, n. 9.637/98, pela Lei n. 13.019/14, intitulada de Marco Regulatório para as Organizações da Sociedade Civil (MROSC).

Após o processo de impeachment que destituiu a presidente Dilma de seu segundo mandato, em 2016, o seu vice-presidente, Michel Temer, do Partido Movimento Democrático Brasileiro (PMDB), assumiu a gestão do País, firmando o compromisso de fazê-lo avançar até o ano 2018. Sumariamente, a nova gestão efetivou-se em meio à atual crise econômica mundial e, também, imersa em uma crise política regada a escândalos de corrupção e desesperança nacional.

Nesse contexto, o Governo Temer sinaliza o reforço aos processos de privatização educacional quando propõe executar uma política de desenvolvimento centrada na iniciativa privada, agregando, entre as estratégias, as parcerias para a complementação de serviços públicos, proposição explicitada no documento Uma Ponte Para o Futuro, que se apresenta como uma proposta para a superação da crise que segue avançando no País (PARTIDO MOVIMENTO DEMOCRÁTICO BRASILEIRO, 2015).

A gestão das políticas educacionais, em todas as conjunturas políticas retratadas, efetiva-se nos moldes instrumentais, corroborando os interesses do capital e não para o alcance dos fins educacionais. Para Gramsci (1982), a função da escola é assegurar a humanização do indivíduo na perspectiva de fomentar o seu pensamento filosófico e, consequentemente, levá-lo a reconhecer-se como sujeito histórico capaz de contribuir ativamente no processo de transformação social.

Nesse sentido, a escola é um espaço em potencial de formação política e ideológica, sendo, portanto, ambiente de disputa daqueles que pretendem enraizar a 
legitimação de seus ideais e a naturalização de seus pressupostos. De maneira geral, as estratégias executadas no âmbito educacional brasileiro traduzem o pensamento hegemônico capitalista como tentativa de superação da crise e conservação do sistema.

A escola, nesse contexto, constitui-se como importante aparelho ideológico do Estado no processo de reestruturação do capital, uma vez que a lógica mercadológica imbricada na gestão de políticas educacionais se efetiva em favor de sua manutenção, disseminando, por meio da inculcação de premissas como a individualidade e a competência como fatores determinantes para a mudança do status quo, a naturalização das desigualdades sociais.

\section{A EXPANSÃO DAS PARCERIAS COM ORGANIZAÇÕES DA SOCIEDADE CIVIL: O NACIONAL E O LOCAL EM DISCUSSÃO}

No Brasil, a reconfiguração estatal a partir das reformas mencionadas favoreceu o aumento volumétrico de entidades do Terceiro Setor atuando em diversos campos das políticas sociais e educacionais financiadas pela União, pelos estados e pelos municípios. A pesquisa intitulada As Fundações Privadas e Associações Sem Fins Lucrativos no Brasil 2010 (FASFIL), realizada pelo Instituto Brasileiro de Geografia e Estatística (IBGE), no ano 2012, informa a acelerada expansão do Terceiro Setor no Brasil, conforme o Gráfico 1:

Gráfico 1 - Expansão do Terceiro Setor no Brasil, por década (1970-2010)

- runaaçoesprivadase associações sem fins lucrativos; 2010; 118.653

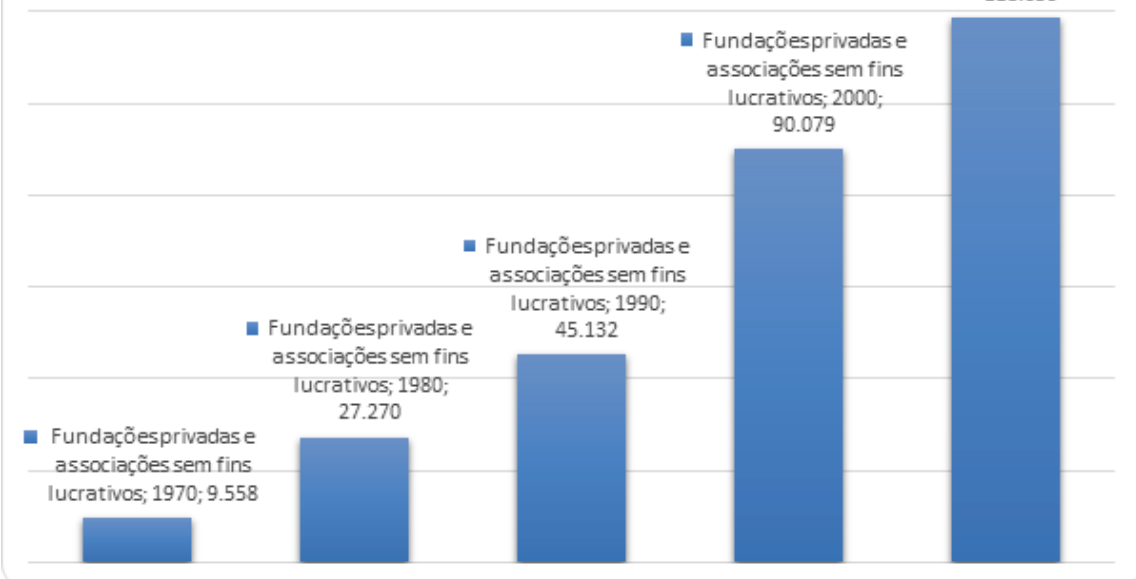

Fonte: elaborado pelos autores com base no IBGE (2012). 
O Gráfico 1 revela o aumento expressivo das OSC em âmbito nacional desde a década de 1970. De 1990 a 2000, duplica-se o número de entidades do Terceiro Setor, mantendo-se a margem de crescimento na década seguinte. Essa evolução deve-se aos incentivos governamentais de fomento às parcerias pós-Reforma Estatal dos anos 1990, conforme explicitado anteriormente.

Colaborando com os dados do IBGE, o Mapa das Organizações da Sociedade Civil (MOSC) informa que as instituições do Terceiro Setor continuam a se expandir rapidamente, assim como a celebração de parcerias com o setor público. Respectivamente, no ano 2017 , foram registradas 444.305 entidades em todo o território nacional, sendo contabilizadas 16.264 parcerias firmadas no âmbito do Governo federal (INSTITUTO DE PESQUISAS ECONÔMICAS APLICADAS, 2017).

Peroni e Silva (2013) informam que a intensificação de parcerias entre o setor público e as organizações de iniciativa privada para oferta das políticas educacionais tem se efetivado por meio de múltiplas ações e em grande parte dos estados e municípios do País. Essa realidade também foi verificada no contexto da Semec de Teresina, PI, órgão da administração direta responsável pela oferta da Educação Infantil, do Ensino Fundamental, da Educação de Jovens e Adultos (EJA), pela assistência ao educando e pela administração escolar na esfera da Rede Municipal de Ensino.

O Município de Teresina, com uma população de 814.230 habitantes (IBGE, 2017), é a capital do Piauí. O Índice de Desenvolvimento Humano Municipal (IDHM) do referido Estado, em 2010, contabilizou um total de 0,646 pontos situando essa Unidade Federativa (UF) na faixa média do IDHM brasileiro. É importante pontuar que, entre as dimensões que contribuíram para esse patamar de desenvolvimento da UF, estão a longevidade, com índice de 0,777, seguida da renda, com índice de 0,635, e, posteriormente a educação com índice de 0,547 (ATLAS DO DESENVOLVIMENTO HUMANO NO BRASIL, 2017a).

Especificamente, possuindo um IDHM educacional de 0,707 pontos como mostram dados do ano 2010, a capital do Piauí possui uma faixa de desenvolvimento humano considerada alta (ATLAS DO DESENVOLVIMENTO HUMANO NO BRASIL, 2017b). No que se refere à oferta educativa, o Município de Teresina matriculou, em 2016, nos seus 300 estabelecimentos de ensino, 20.817 crianças na Educação Infantil, 54.933 no Ensino Fundamental e 3.816 estudantes da EJA (INSTITUTO NACIONAL DE ESTUDOS E PESQUISAS EDUCACIONAIS ANÍSIO TEIXEIRA, 2017).

Sumariamente, apesar do avanço no que diz respeito à acessibilidade educacional, conforme mostram dados do Observatório do Plano Nacional de Educação 
(2017), paralelamente, a sua oferta qualitativa é questionável na medida em que o Município em estudo permite a privatização do ensino ao adquirir, por meio da compra, materiais e/ou sistemas apostilados de ensino do setor privado. As referidas aquisições podem ser verificadas no Quadro 1 a seguir:

Quadro 1 - Expansão das parcerias entre a Semec e Organizações da Sociedade Civil

\begin{tabular}{|c|c|c|c|c|}
\hline OSC & $\begin{array}{c}\text { Ano de Ce- } \\
\text { lebração }\end{array}$ & Situação & $\begin{array}{l}\text { Área de atu- } \\
\quad \text { ação }\end{array}$ & Proposta \\
\hline $\begin{array}{l}\text { Instituto Ayr- } \\
\text { ton Senna } \\
\text { (IAS) }\end{array}$ & 2001 & $\begin{array}{l}\text { Em } \\
\text { vigência }\end{array}$ & $\begin{array}{l}\text { Ensino Funda- } \\
\text { mental: séries } \\
\text { iniciais }\left(2^{\circ} \text { ao } 5^{\circ}\right. \\
\text { ano) e finais ( } 8^{\circ} \\
\text { ano) }\end{array}$ & $\begin{array}{l}\text { Programas de gestão, } \\
\text { correção de fluxo, distor- } \\
\text { ção idade-série, avalia- } \\
\text { ção, oferta de material } \\
\text { didático e formações para } \\
\text { técnicos da secretaria, } \\
\text { gestores, pedagogos e } \\
\text { docentes. }\end{array}$ \\
\hline $\begin{array}{l}\text { Instituto Alfa } \\
\text { e Beto (IAB) }\end{array}$ & 2003 & $\begin{array}{l}\text { Em } \\
\text { vigência }\end{array}$ & $\begin{array}{l}\text { Ensino Funda- } \\
\text { mental: séries } \\
\text { iniciais } 1^{\circ}, 2^{\circ} \text {, } \\
3^{\circ}, 4^{\circ}, 5^{\circ} \text { e } 9^{\circ} \\
\text { anos }\end{array}$ & $\begin{array}{l}\text { Implantação do Programa } \\
\text { Alfa e Beto para o } 1^{\circ} \text { ano } \\
\text { e IAB Prova Brasil para } \\
\text { a aquisição de materiais } \\
\text { didáticos e suporte para } \\
\text { avaliações, capacitação } \\
\text { para técnicos da Semec e } \\
\text { docentes da rede. }\end{array}$ \\
\hline $\begin{array}{l}\text { Instituto Alfa } \\
\text { e Beto (IAB) }\end{array}$ & 2014 & $\begin{array}{l}\text { Em } \\
\text { vigência }\end{array}$ & $\begin{array}{l}\text { Educação Infan- } \\
\text { til: etapa final da } \\
\text { pré-escola }\left(2^{\circ}\right. \\
\text { período) }\end{array}$ & $\begin{array}{l}\text { Implantação do Programa } \\
\text { Alfa e Beto Pré-escola } \\
\text { para a aquisição de } \\
\text { materiais didáticos e } \\
\text { suporte para avaliações, } \\
\text { capacitação para técnicos } \\
\text { da Semec e docentes da } \\
\text { rede. }\end{array}$ \\
\hline $\begin{array}{l}\text { Integração: } \\
\text { Empresa-Es- } \\
\text { cola (CIEE), } \\
\text { Fundação } \\
\text { Roberto Ma- } \\
\text { rinho (FRM) } \\
\text { e empresas } \\
\text { parceiras }\end{array}$ & 2003 & $\begin{array}{l}\text { Em } \\
\text { vigência }\end{array}$ & $\begin{array}{l}\text { Jovens com } \\
\text { idades entre } 14 \text { e } \\
24 \text { anos }\end{array}$ & $\begin{array}{l}\text { Implantação do Programa } \\
\text { Aprendiz Legal para a } \\
\text { formação profissional em } \\
\text { nove modalidades: auxi- } \\
\text { liar de produção, auxiliar } \\
\text { de alimentação, comércio } \\
\text { e varejo, gestão pública, } \\
\text { logística, ocupações } \\
\text { administrativas, práticas } \\
\text { bancárias, telesserviços e } \\
\text { turismo. }\end{array}$ \\
\hline
\end{tabular}




\begin{tabular}{|c|c|c|c|c|}
\hline OSC & $\begin{array}{l}\text { Ano de Ce- } \\
\text { lebração }\end{array}$ & Situação & $\begin{array}{l}\text { Área de atu- } \\
\text { ação }\end{array}$ & Proposta \\
\hline $\begin{array}{l}\text { ONG Alfa- } \\
\text { betização } \\
\text { Solidária } \\
\text { (Alfasol) }\end{array}$ & 2006 & $\begin{array}{l}\text { Em } \\
\text { vigência }\end{array}$ & $\begin{array}{l}\text { Alfabetização de } \\
\text { jovens e adultos } \\
\text { com idades aci- } \\
\text { ma de } 15 \text { anos }\end{array}$ & $\begin{array}{l}\text { Implantação dos progra- } \\
\text { mas TeleSol e Telesol Pro } \\
\text { para a formação inicial e } \\
\text { continuada de gestores, } \\
\text { pedagogos, professores } \\
\text { de } 1^{\circ} \text { e } 2^{\circ} \text { segmentos da } \\
\text { EJA e colaboradores; } \\
\text { formação e acompa- } \\
\text { nhamento pedagógico } \\
\text { sistemático nas escolas; } \\
\text { desenvolvimento do } \\
\text { curso de educação pro- } \\
\text { fissional, em ocupações } \\
\text { administrativas, teleservi- } \\
\text { ços, empreendedorismo e } \\
\text { logística. }\end{array}$ \\
\hline $\begin{array}{l}\text { Fundação } \\
\text { Nestlé }\end{array}$ & 2007 & $\begin{array}{l}\text { Em } \\
\text { vigência }\end{array}$ & $\begin{array}{l}\text { Ensino Funda- } \\
\text { mental }\end{array}$ & $\begin{array}{l}\text { Implantação do Projeto } \\
\text { Nutrir para a reeducação } \\
\text { alimentar dos alunos. }\end{array}$ \\
\hline $\begin{array}{l}\text { Instituto } \\
\text { C\&A e ONG } \\
\text { Avante - } \\
\text { Educação e } \\
\text { Mobilização } \\
\text { Social }\end{array}$ & 2010 & $\begin{array}{l}\text { Encer- } \\
\text { rada }\end{array}$ & $\begin{array}{l}\text { Educação } \\
\text { Infantil ( } 0 \text { aos } 5 \\
\text { anos) }\end{array}$ & $\begin{array}{l}\text { Implantação do Projeto } \\
\text { Paralápracá, enfocando } \\
\text { um trabalho voltado } \\
\text { para atividades lúdicas, } \\
\text { por meio da formação } \\
\text { continuada de professo- } \\
\text { res e acesso a materiais } \\
\text { pedagógicos. }\end{array}$ \\
\hline $\begin{array}{l}\text { Instituto } \\
\text { Qualidade } \\
\text { no Ensino } \\
\text { (IQE) }\end{array}$ & 2010 & $\begin{array}{l}\text { Encer- } \\
\text { rada }\end{array}$ & $\begin{array}{l}\text { Ensino Funda- } \\
\text { mental }\left(6^{\circ} \text { ao } 9^{\circ}\right. \\
\text { ano })\end{array}$ & $\begin{array}{l}\text { Implantação do Programa } \\
\text { Qualiescola para inter- } \\
\text { venção nas disciplinas de } \\
\text { português, matemática, } \\
\text { ciências e geografia, por } \\
\text { meio da promoção de } \\
\text { capacitação dos forma- } \\
\text { dores dos professores } \\
\text { da Secretaria, fortaleci- } \\
\text { mento da gestão escolar, } \\
\text { avaliação de desempenho } \\
\text { dos alunos, atividades } \\
\text { de articulação com a } \\
\text { comunidade. }\end{array}$ \\
\hline
\end{tabular}




\begin{tabular}{|c|c|c|c|c|}
\hline OSC & $\begin{array}{c}\text { Ano de Ce- } \\
\text { lebração }\end{array}$ & Situação & $\begin{array}{l}\text { Área de atu- } \\
\text { ação }\end{array}$ & Proposta \\
\hline $\begin{array}{l}\text { Fundação } \\
\text { Volksvagen }\end{array}$ & 2013 & $\begin{array}{l}\text { Em } \\
\text { vigência }\end{array}$ & $\begin{array}{l}\text { Educação } \\
\text { Infantil ( } 0 \text { aos } 5 \\
\text { anos) }\end{array}$ & $\begin{array}{l}\text { Implantação do Projeto } \\
\text { Brincar para a formação } \\
\text { de professores, coor- } \\
\text { denadores, diretores e } \\
\text { técnicos das secretarias. } \\
\text { Objetiva favorecer a } \\
\text { reflexão sobre concepção } \\
\text { e cultura infantil, tendo } \\
\text { como base o brincar, e } \\
\text { o letramento como tema } \\
\text { central. }\end{array}$ \\
\hline $\begin{array}{l}\text { A Junior } \\
\text { Achievement } \\
\text { (JA) }\end{array}$ & 2014 & $\begin{array}{l}\text { Em } \\
\text { vigência }\end{array}$ & $\begin{array}{l}\text { Ensino Funda- } \\
\text { mental ( } 4^{\circ} \text { ao } 9^{\circ} \\
\text { ano) }\end{array}$ & $\begin{array}{l}\text { Implantação do Projeto } \\
\text { Nosso Planeta, Nossa } \\
\text { Casa, que objetiva cons- } \\
\text { cientizar os jovens sobre } \\
\text { a importância do desen- } \\
\text { volvimento sustentável e } \\
\text { do consumo consciente. }\end{array}$ \\
\hline $\begin{array}{l}\text { Casas Bahia } \\
\text { (Fundação } \\
\text { Via Varejo) }\end{array}$ & 2015 & $\begin{array}{l}\text { Encer- } \\
\text { rada }\end{array}$ & $\begin{array}{l}\text { Educação de } \\
\text { Jovens e Adultos }\end{array}$ & $\begin{array}{l}\text { Implantação do Projeto } \\
\text { Aprender e Transfor- } \\
\text { mar para promoção de } \\
\text { cursos gratuitos, sem } \\
\text { limite de idade, nas áreas } \\
\text { de empreendedorismo, } \\
\text { informática, e emprega- } \\
\text { bilidade, com certificados } \\
\text { de participação. }\end{array}$ \\
\hline
\end{tabular}

Fonte: elaborado pelos autores com base no site da Semec (ALUNOS...2013; FORMADOS..., 2013; PROGRAMA..., 2013a, 2013b; SEMEC..., 2013a, 2013b, 2013c, 2014a, 2014b; SAÚDE..., 2008; TERESINA..., 2013; TURMAS..., 2013).

Nota: Apesar de o site da Semec conter informações sobre as parcerias, somente foi possível verificar o ano da celebração da parceria entre a Secretaria em estudo e a Fundação Nestlé por meio do site da Istoé negócio (SAÚDE..., 2008). O período de vigência das parcerias foi mensurado considerando que as notícias sobre as ações não eram mais anunciadas nos sites pesquisados.

As parcerias firmadas entre a Semec e as OSC nos anos 2001 a 2015 contabilizam 11, sendo duas encerradas e nove em vigência. Para a Educação Infantil, são direcionados 27,2\% dos conveniamentos; para o Ensino Fundamental, 45,4\%; e para a Educação de Jovens e Adultos (EJA), 27,2\%. Como se pode observar, a maior parte das parcerias são destinadas ao Ensino Fundamental. 
O Quadro 1 mostra que entre as propostas voltadas para a Educação Infantil, encontram-se formação docente, avaliação e gestão, bem como oferta de material didático. Essas propostas são identificadas, igualmente, no Ensino Fundamental, agregando-se a elas formações para os discentes acerca de desenvolvimento sustentável e reeducação alimentar. $\mathrm{Na}$ EJA, observam-se ações voltadas para a formação de professores e gestores escolares (diretor, pedagogo) e acompanhamento pedagógico. É fundamental pontuar que, nessa modalidade de ensino, é intensa a oferta de capacitações aos discentes, por meio de cursos profissionalizantes voltados para ocupações administrativas, empreendedorismo e informática.

As ações propostas por esse volume de parcerias exemplificam a incorporação e efetivação, em âmbito nacional e local, das orientações da agenda internacional para a educação, as quais fomentam o mercado, como problematizado por Libâneo, Oliveira e Toschi (2012).

Tal similaridade descobre-se, sobretudo, a partir da prática de parceria entre o setor público e o setor privado, considerando a eficiência e a eficácia da oferta do ensino, bem como a partir do teor das propostas dos programas das OSC, que acabam conduzindo as políticas públicas de ensino, por meio de interferências na formação de professores, no currículo, na avaliação e na gestão de unidades escolares.

Em muitos casos, a intervenção nos campos supracitados materializa-se nas propostas de sistemas de ensino apostilados, ofertados pelas OSC. Conforme conceituado anteriormente, os sistemas de ensino são programas idealizados por empresas ou organizações da iniciativa privada que ofertam pacotes educacionais contemplando materiais didáticos e assessorias externas para redes educacionais (ADRIÃO et al., 2009). A compra de sistemas apostilados resulta na privatização da educação pública, já que as políticas de ensino passam a ser pensadas e conduzidas pelo setor privado, como tratado por Adrião et al. (2009).

Nesse nível de discussão, a Semec apresenta-se como um espaço de privatização do tipo exógena, nos termos de Ball e Youdell (2008), pois expande e fortalece parcerias com as OSC, bem como abre espaço para a inserção de políticas privadas de ensino por meio da aquisição de material didático, formação docente, assessoria técnica e tecnologias, especialmente com o Instituto Ayrton Senna e o Instituto Alfa e Beto.

Na perspectiva de caracterizar essa expansão e os seus reflexos para a política educacional da rede em discussão, na próxima seção aborda-se o conveniamento entre a Semec e o Instituto Alfa e Beto, por representar um expressivo fortalecimento dessa relação, ao inserir seus programas no âmbito da educação municipal, nas eta- 
pas de oferta constitucionalmente obrigatórias: o Ensino Fundamental e a Educação Infantil.

\section{EXPANSÃO DAS PARCERIAS NA REDE MUNICIPAL DE EDUCAÇÃO: O INSTITUTO ALFA E BETO (IAB) EM FOCO}

O IAB é uma organização não governamental sem fins lucrativos, com sede em Minas Gerais. Baseado no arcabouço teórico de economistas, neurologistas, psiquiatras e sociólogos, como Knudsen et al. (2006), conforme informações do site institucional, o Instituto objetiva a produção de capital humano por meio de ações que visam a "contribuir com evidências e análises sobre o que funciona em educação para qualificar o debate e promover uma transformação nas políticas e práticas, mobilizando setores importantes da sociedade para o avanço da educação." (INSTITUTO ALFA E BETO, 2016).

Atualmente, visando a essa transformação, o IAB celebra parceria com 36 secretarias municipais de educação brasileiras, divididas em 13 estados, entre os quais estão Alagoas, Bahia, Ceará, Maranhão, Minas Gerais, Pará, Pernambuco, Paraná, Roraima, Rio Grande do Sul e Sergipe (INSTITUTO ALFA E BETO, 2016). Para o alcance de seus objetivos, o Instituto conta com duas unidades distintas, quais sejam: IDados, que se caracteriza por ser uma Instituição associada ao IAB, que objetiva informar e lançar questões para promoção de debate educacional; e o Alfa e Beto Soluções, responsável pelo desenvolvimento e pela implementação de soluções pedagógicas em redes de ensino e instituições de Educação Infantil e Ensino Fundamental (alfabetização e séries iniciais) (INSTITUTO ALFA E BETO, 2016).

O firmamento de parceria entre a Semec de Teresina, PI, e o referido Instituto data do ano 2003, com propostas de intervenções para as séries iniciais do Ensino Fundamental, mediante aquisição de materiais do Programa Alfa e Beto (PROGRAMA..., 2013a). Atualmente, as ações do Instituto abrangem o $1^{\circ}, 2^{\circ}, 3^{\circ}, 4^{\circ}, 5^{\circ}$ e $9^{\circ}$ anos do Ensino Fundamental, agregando outros programas, como a Prova Brasil, preparatório para os exames nacionais em larga escala.

Em 2014, o IAB expandiu-se para a etapa final da Educação Infantil, que atende a crianças de cinco anos de idade. Em 2016, a implantação do Programa já compreende dois terços dos 151 Centros de Educação Infantil, totalizando 100 unidades. De acordo com a Semec (TERESINA, 2015), a expansão dessa proposta para a Educação Infantil é justificada pela necessidade de a Secretaria intensificar as ações em favor da alfabetização, introduzindo uma série de novos programas que devem 
apoiar as escolas na superação de desafios, a exemplo da infrequência dos alunos e reprovação escolar. Assim, a Educação Infantil limita-se a um caráter propedêutico de preparação para a sua etapa subsequente.

A parceria entre a Rede Municipal de Educação e o Instituto Alfa e Beto materializa-se por meio da celebração de contratos anuais entre as partes, desde o ano 2003, com amparo dos dois convênios assinados, nos anos 2003 e 2014. A expansão dos Programas do IAB na referida Secretaria explicita um crescente investimento financeiro, como pode ser verificado no Quadro 2.

Quadro 2 - Contratos entre Semec e IAB - 2003 a 2016

\begin{tabular}{|c|c|c|c|c|}
\hline $\begin{array}{l}\text { N. contra- } \\
\text { to/ano }\end{array}$ & Objeto & $\begin{array}{l}\text { Ano de } \\
\text { imple- } \\
\text { menta- } \\
\text { ção }\end{array}$ & $\begin{array}{l}\text { Valores nomi- } \\
\text { nais }\end{array}$ & Valores reais* \\
\hline $021 / 2003$ & $\begin{array}{l}\text { Conjunto completo de } \\
\text { materiais que integram o } \\
\text { Programa Alfa e Beto de } \\
\text { Alfabetização para o Ensi- } \\
\text { no Fundamental. }\end{array}$ & 2003 & Não informado & Não informado \\
\hline $011 / 2004$ & $\begin{array}{l}\text { Conjunto completo de } \\
\text { materiais que integram o } \\
\text { Programa Alfa e Beto de } \\
\text { Alfabetização para o Ensi- } \\
\text { no Fundamental. }\end{array}$ & 2004 & $\mathrm{R} \$ 71.760,00$ & $\mathrm{R} \$ 151.697,47$ \\
\hline $003 / 2005$ & $\begin{array}{l}\text { Conjunto completo de } \\
\text { materiais que integram o } \\
\text { Programa Alfa e Beto de } \\
\text { Alfabetização para o Ensi- } \\
\text { no Fundamental. }\end{array}$ & 2005 & $\mathrm{R} \$ 118.860,00$ & $\mathrm{R} \$ 238.709,70$ \\
\hline $016 / 2006$ & $\begin{array}{l}\text { Conjunto completo de } \\
\text { materiais que integram o } \\
\text { Programa Alfa e Beto de } \\
\text { Alfabetização para o Ensi- } \\
\text { no Fundamental. }\end{array}$ & 2006 & $\mathrm{R} \$ 262.482,98$ & $\mathrm{R} \$ 499.923,06$ \\
\hline $220 / 2006$ & $\begin{array}{l}\text { Conjunto das unidades I } \\
\text { e II, que integram o Pro- } \\
\text { grama Alfa e Beto de Al- } \\
\text { fabetização para o Ensino } \\
\text { Fundamental. }\end{array}$ & 2007 & $\mathrm{R} \$ 475.600,84$ & $\mathrm{R} \$ 884.386,37$ \\
\hline
\end{tabular}




\begin{tabular}{|c|c|c|c|c|}
\hline $\begin{array}{l}\text { N. contra- } \\
\text { to/ano }\end{array}$ & Objeto & $\begin{array}{l}\text { Ano de } \\
\text { imple- } \\
\text { menta- } \\
\text { ção }\end{array}$ & $\begin{array}{l}\text { Valores nomi- } \\
\text { nais }\end{array}$ & Valores reais* \\
\hline $001 / 2008$ & $\begin{array}{l}\text { Conjunto dos materiais do } \\
\text { Programa Alfa e Beto de } \\
\text { Alfabetização para o Ensi- } \\
\text { no Fundamental. }\end{array}$ & 2008 & $\mathrm{R} \$ 424.310,40$ & $\mathrm{R} \$ 750.326,41$ \\
\hline $047 / 2009$ & $\begin{array}{l}\text { Conjunto dos materiais do } \\
\text { Programa Alfa e Beto de } \\
\text { Alfabetização para o Ensi- } \\
\text { no Fundamental. }\end{array}$ & 2009 & $\mathrm{R} \$ 535.224,00$ & $\mathrm{R} \$ 880.467,51$ \\
\hline $008 / 2010$ & $\begin{array}{l}\text { Conjunto dos materiais do } \\
\text { Programa Alfa e Beto de } \\
\text { Alfabetização para o Ensi- } \\
\text { no Fundamental. }\end{array}$ & 2010 & $\mathrm{R} \$ 579.010,00$ & $\mathrm{R} \$ 915.514,81$ \\
\hline $001 / 2011$ & $\begin{array}{l}\text { Aquisição dos materiais } \\
\text { destinados ao Programa } \\
\text { Alfa e Beto de Alfabetiza- } \\
\text { ção para o Ensino Funda- } \\
\text { mental. }\end{array}$ & 2011 & $\mathrm{R} \$ 655.290,00$ & $\mathrm{R} \$ 972.628,40$ \\
\hline $003 / 2012$ & $\begin{array}{l}\text { Conjunto dos materiais do } \\
\text { Programa Alfa e Beto de } \\
\text { Alfabetização para o Ensi- } \\
\text { no Fundamental. }\end{array}$ & 2012 & $\mathrm{R} \$ 669.600,00$ & $\mathrm{R} \$ 945.712,37$ \\
\hline $021 / 2013$ & $\begin{array}{l}\text { Aquisição de materiais do } \\
\text { Instituto Alfa e Beto para } \\
\text { utilização didática desti- } \\
\text { nada às escolas da rede } \\
\text { municipal de educação }\end{array}$ & & & \\
\hline $072 / 2013$ & $\begin{array}{l}\text { Aquisição de materiais } \\
\text { para o Programa de Revi- } \\
\text { são do } 3^{\circ} \text { ano e Programa } \\
\text { Prova Brasil } 5^{\circ} \text { ano do En- } \\
\text { sino Fundamental. }\end{array}$ & 2013 & $\mathrm{R} \$ 1.783 .532,00$ & $\mathrm{R} \$ 2.289 .465,34$ \\
\hline
\end{tabular}




\begin{tabular}{|c|c|c|c|c|}
\hline $\begin{array}{l}\text { N. contra- } \\
\text { to/ano }\end{array}$ & Objeto & $\begin{array}{l}\text { Ano de } \\
\text { imple- } \\
\text { menta- } \\
\text { ção }\end{array}$ & $\begin{array}{l}\text { Valores nomi- } \\
\text { nais }\end{array}$ & Valores reais* \\
\hline $186 / 2013$ & $\begin{array}{l}\text { Aquisição de materiais } \\
\text { do Programa Alfa e Beto } \\
\text { de Pré-escola II para a } \\
\text { Educação Infantil; do Pro- } \\
\text { grama IAB Prova Brasil } \\
4^{\circ} \text { ano; do Programa IAB } \\
\text { Prova Brasil } 5^{\circ} \text { ano; e do } \\
\text { Programa Intensivo de Al- } \\
\text { fabetização para os alunos } \\
\text { e professores do Ensino } \\
\text { Fundamental. }\end{array}$ & 2014 & $\mathrm{R} \$ 2.666 .553,00$ & $\mathrm{R} \$ 3.359 .449,06$ \\
\hline $221 / 2015$ & $\begin{array}{l}\text { Aquisição de } 1.000 \text { licen- } \\
\text { ças de uso do software } \\
\text { digital Galáxia Alfa para o } \\
\text { ano letivo de } 2015 \text {. }\end{array}$ & 2015 & $\mathrm{R} \$ 150.000,00$ & $\mathrm{R} \$ 165.193,38$ \\
\hline $017 / 2016$ & $\begin{array}{l}\text { Aquisição de material di- } \\
\text { dático do Programa Alfa } \\
\text { e Beto; prestação de ser- } \\
\text { viços de disponibilização } \\
\text { de } 1.750 \text { (mil setecentas } \\
\text { e cinquenta) licenças de } \\
\text { uso do software digital } \\
\text { Galáxia Alfa; aquisição } \\
\text { de } 280 \text { IAB Testes (Testes } \\
\text { Digital). }\end{array}$ & 2016 & $\mathrm{R} \$ 1.765 .393,00$ & $\mathrm{R} \$ 1.853 .566,44$ \\
\hline
\end{tabular}

Os dados apresentados no Quadro 2 mostram que, no decorrer de 14 anos, entre 2003 e 2016, foram assinados 15 contratos para a aquisição de diversos programas do IAB, com destaque para o Programa Alfa e Beto. O sistema de apostilamento fica explícito na maioria dos contratos, inicialmente para o Ensino Fundamental e, posteriormente, para a Educação Infantil. Ademais, licenças para uso de software, programa de apoio para a preparação de alunos para os testes em larga escala, bem como a aquisição do IAB Testes Digital para a avaliação de alunos da rede de ensino seguem desde 2013. 
Infere-se, portanto, que a Rede Municipal de Educação de Teresina fomenta a privatização exógena e endógena, com a inserção volumétrica de tecnologias de ensino do Instituto, destacando-se os materiais do Programa Alfa e Beto, bem como pela incorporação da gestão de resultados do setor privado por meio da aquisição de testes avaliativos padronizados.

No que se refere aos gastos para a manutenção da parceria, considerando-se o ano de implementação dos programas adquiridos por meio de contratos nesse mesmo intervalo de tempo, observa-se um crescimento dos repasses, com destaque para os anos 2014 e 2016, e isoladas baixas, tal qual demonstra o Gráfico 2.

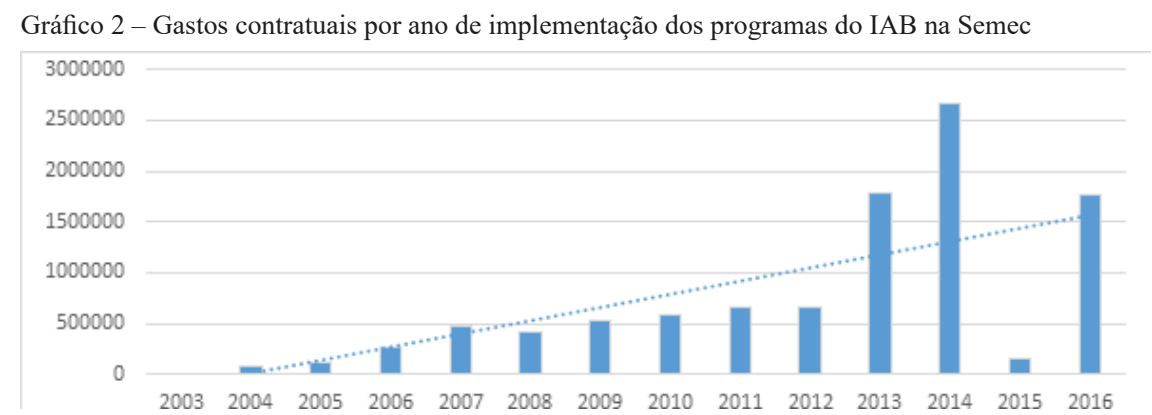

Fonte: elaborado pelos autores com base nos Diários Oficiais do Município de Teresina (TERESINA, 20032016).

Contabilizando os gastos com a parceria entre a Secretaria Municipal de Educação e o Instituto Alfa e Beto, entre os anos 2003 e 2016, obtém-se um investimento, em valores nominais, de R\$ 10.157.616,22 (dez milhões, cento e cinquenta e sete mil, seiscentos e dezesseis reais e vinte e dois centavos), o que denota um expressivo avanço e fortalecimento da parceria. O fomento da expansão da parceria, por meio da celebração de contratos entre a Semec e o IAB, permanece em vigência e intensifica-se nos anos posteriores ao recorte temporal do presente artigo, dada a identificação, nos Diários Oficiais pesquisados, de investimento financeiro referente ao contrato $\mathrm{n}$. 473/2016, no valor de R\$ 6.060.628,00 (seis milhões, sessenta mil e seiscentos e vinte e oito reais) para a implementação, em 2017, dos programas do Instituto. Esse valor representa cerca de $60 \%$ do total investido em 14 anos, entre 2003 e 2016, revelando que a Semec considera as políticas fomentadas pelas parceiras adequadas para as necessidades educacionais da rede.

De maneira geral, os recursos envolvidos na parceria são advindos do montante vinculado à manutenção e ao desenvolvimento do ensino. No entanto, considerando que Teresina é contemplada com o Programa Nacional do Livro Didático 
(PNLD), a expansão das parcerias para a compra de sistemas apostilados resulta em um duplo investimento no setor, conforme indica pesquisa realizada por Adrião et al. (2015), colocando em xeque a suposta eficiência do gasto público, decorrente da inserção da lógica privada na gestão do Estado, aspecto tão propagado pelo ideário neoliberal.

Em suma, a adoção de sistemas apostilados, além de assegurar a privatização exógena da educação pública com a implantação de políticas educacionais privadas, onera financeiramente a Secretaria de educação ora pesquisada, bem como, corroborando com Ball e Youdell (2008), a torna fonte de lucro do setor privado.

\section{ALGUMAS CONCLUSÕES}

A realidade educacional do Município de Teresina, PI, carrega, em seu bojo, reflexos das transformações desencadeadas a partir da Reforma Estatal dos anos 1990 realizadas no Brasil, como consequência dos ditames internacionais no movimento de recomposição da crise do sistema capitalista.

Esse contexto fundamenta a prática de parcerias entre setor público e instituições privadas, a partir de mecanismos de descentralização das responsabilidades sobre a oferta de políticas sociais, consideradas necessárias à eficiência e eficácia dos serviços. Nesse processo de busca, as políticas educacionais são submetidas à inserção da lógica privada, mediante sistemas endógenos e exógenos de privatização, visando à manutenção do mercado global, por meio da produção de capital humano.

A Semec, nesse contexto, assim como ocorre em outros municípios brasileiros, vivencia a expansão e o fortalecimento de parcerias com instituições da iniciativa privada e, consequentemente, adere a processos de privatização da educação pública, implantando políticas pensadas pelo setor privado, visando a um questionável avanço qualitativo da educação a partir de sistemas padronizados de ensino. Assim, a privatização da gestão das políticas atende qualitativamente ao mercado e, em contrapartida, nega a efetivação do direito à educação pública humanizada, considerando a transformação social.

De maneira geral, a discussão sobre a privatização da educação pública, por intermédio da compra de sistemas apostilados de ensino, não se esgota na ideia de expansão, sendo necessário descobrir como as interferências do Terceiro Setor se efetivam como propostas para a gestão da educação pública, bem como as contradições dessa inserção, no que se refere à garantia do direito à educação de qualidade. 
Nesse diapasão, demandam-se novos estudos que explicitem as consequências dos processos de privatização da educação, a fim de fortalecer o debate em defesa de uma educação eminentemente pública e de qualidade.

\section{REFERÊNCIAS}

ADRIÃO, T. M. de F. et al. Sistema de ensino privado na educação pública brasileira: consequências da mercantilização para o direito à educação. 2015. Relatório de pesquisa. Disponível em: <http://flacso.org.br/files/2016/04/Peri-Sistemas-de-Ensino-Privado-na-Educa $\% \mathrm{C} 3 \% \mathrm{~A} 7 \% \mathrm{C} 3 \% \mathrm{~A} 30-\mathrm{P} \% \mathrm{C} 3 \%$ BAblica-Brasileira-ok. pdf $>$. Acesso em: 02 jun. 2017.

ADRIÃO, T. M. de F. et al. Uma modalidade peculiar de privatização da educação pública: a aquisição de sistemas de ensino por municípios paulistas. Educação e Sociedade, v. 30, n. 108, p. 799-818, out. 2009.

ADRIÃO, T. M. de F.; PERONI, V. M. V. Público não-estatal: estratégias para o setor educacional brasileiro. In: ADRIÃO, T. M. de F.; PERONI, V. M. V. (Org.). O público e o privado em educação: interfaces entre Estado e sociedade. São Paulo: Xamã, 2005. p. 137-153.

ALFABETIZAÇÃO é prioridade nas escolas da Prefeitura de Teresina. Prefeitura Municipal de Teresina, 2014. Disponível em: <http://www.portalpmt.teresina.pi.gov. br/noticia/Alfabetizacao-e-prioridade-nas-escolas-da-Prefeitura-de-Teresina/2167>. Acesso em: 29 out. 2015.

ATLAS DO DESENVOLVIMENTO HUMANO NO BRASIL. Índice de Desenvolvimento Humano (IDHM) do Piauí. Disponível em: $<$ http://atlasbrasil.org. br/2013/pt/perfil_uf/piaui>. Acesso em: 10 fev. 2017a.

ATLAS DO DESENVOLVIMENTO HUMANO NO BRASIL. Índice de Desenvolvimento Humano (IDH) educacional de Teresina-PI. Disponível em: $<$ http://atlasbrasil.org.br/2013/pt/ranking > . Acesso em: 10 fev. 2017 b.

ALUNOS da EJA podem se qualificar através do projeto Aprender e Transformar. Semec - Secretaria Municipal de Educação, Teresina, 2015. Disponível em: $<$ http://www.semec.pi.gov.br/Normal/alunos-da-eja-podem-se-qualificar-atraves-do-projeto-aprender-e-transformar.html>. Acesso em: 17 dez. 2016.

BALL, S.; YOUDELL, D. Hidden privatization in public education. 2008. Disponível em: < http://www.campaignforeducation.org/docs/privatisation/Endogenous $\% 20$ Privatization $\% 20$ Stephen $\% 20$ Ball_ENGLISH.pdf $>$. Acesso em: 10 maio 2016. 
BATISTA, P. N. O consenso de Washington: a visão neoliberal dos problemas latino-americanos. São Paulo: Consulta Popular, 2001.

BRASIL. Lei n. 9.608, de 18 de fevereiro de 1998. Dispõe sobre o serviço voluntário e dá outras providências. Diário Oficial da União, Brasília, DF, 19 fev. 1998. Disponível em: <http://www.planalto.gov.br/ccivil_03/leis/L9608.htm>. Acesso em: 15 jul. 2015.

BRASIL. Lei n. 9.637, de 15 de maio de 1998. Dispõe sobre a qualificação de organizações sociais, a criação do Programa Nacional de Publicização, a extinção dos órgãos e entidades que menciona e a absorção de suas atividades por organizações sociais, e dá outras providências. Diário Oficial da União, Brasília, DF, 18 maio 1998. Disponível em: <http://www.planalto.gov.br/ccivil_03/leis/L9637.htm>. Acesso em: 18 jul. 2015.

BRASIL. Lei n. 9.790, de 23 de março de 1999. Dispõe sobre a qualificação de pessoas jurídicas de direito privado, sem fins lucrativos, como Organizações da Sociedade Civil de Interesse Público, institui e disciplina o Termo de Parceria, e dá outras providências. Diário Oficial da União, Brasília, DF, 24 mar. 1999. Disponível em: $<$ http://www.planalto.gov.br/ccivil_03/leis/L9790.htm>. Acesso em: 14 jul. 2015.

BRASIL. Lei n. 11.079, de 30 de dezembro de 2004. Institui normas gerais para licitação e contratação de parceria público-privada no âmbito da administração pública. Diário Oficial da União, Brasília, DF, 31 dez. 2004. Disponível em: <http://www. planalto.gov.br/ccivil_03/_ato2004-2006/2004/lei/111079.htm>. Acesso em: 05 jul. 2015 .

BRASIL. Lei n. 13.019, de 31 de julho de 2014. Estabelece o regime jurídico das parcerias entre a administração pública e as Organizações da Sociedade Civil, em regime de mútua cooperação, para a consecução de finalidades de interesse público e recíproco, mediante a execução de atividades ou de projetos previamente estabelecidos em planos de trabalho inseridos em termos de colaboração, em termos de fomento ou em acordos de cooperação; define diretrizes para a política de fomento, de colaboração e de cooperação com Organizações da Sociedade Civil; e altera as Leis n. 8.429, de 02 de junho de 1992, e 9.790, de 23 de março de 1999. Diário Oficial da União, Brasília, DF, 01 ago. 2014. Disponível em: <http://www.planalto.gov.br/ ccivil_03/ato2011-2014/2014/lei/113019.htm>. Acesso em: 02 out. 2016.

BRASIL. Plano Diretor de Reforma do Aparelho do Estado - PDRAE. Brasília, DF: Presidência da República, Câmara da Reforma do Estado, Ministério da Administração Federal e Reforma do Estado, 1995.

DRAIBE, S. M. As políticas sociais e o neoliberalismo: reflexões suscitadas pelas experiências latino-americanas. Revista USP, n. 17, p. 86-101, mar./maio 1993. 
FORMADOS jovens do Aprendiz Legal, programa de qualificação profissional. Semec - Secretaria Municipal de Educação, Teresinha, 2013. Disponível em: $<$ http://www.semec.pi.gov.br/Normal/Formados-jovens-do-Aprendiz-Legal-programa-de-qualificacao-profissional.html>. Acesso em: 15 dez. 2016.

GENTILI, P. Neoliberalismo e educação: manual do usuário. In: GENTILI, P; SILVA, T. T.da (Org.). Escola S.A.: quem ganha e quem perde no mercado educacional do neoliberalismo. Brasília, DF: CNTE, 1999.

GRAMSCI, A. Os intelectuais e a organização da cultura. 4. ed. Rio de Janeiro: Civilização Brasileira, 1982.

HARVEY, D. O enigma do capital e as crises do capitalismo. São Paulo: Boitempo, 2011.

IBGE. As fundações privadas e associações sem fins lucrativos no Brasil 2010. 2012. Disponível em: $<\mathrm{ftp}: / / \mathrm{ftp}$.ibge.gov.br/Fundacoes_Privadas_e_Associacoes/2010/fasfil.pdf>. Acesso em: 30 nov. 2016.

IBGE. Habitantes de Teresina, PI. Disponível em: <http://cidades.ibge.gov.br/ xtras/perfil.php?codmun=221100>. Acesso em: 05 fev. 2017.

INSTITUTO ALFA E BETO. IAB 10 anos: resultados. Disponível em: $<$ http://iab10anos.alfaebeto.org.br/subpagina.php?\#resultados>. Acesso em: 10 dez. 2016.

INSTITUTO DE PESQUISAS ECONÔMICAS APLICADAS. Dados indicadores das parcerias entre o Governo Federal e Organizações da Sociedade Civil. Disponível em: $<$ https://mapaosc.ipea.gov.br/dados-indicadores.html $>$. Acesso em: 15 mar. 2017.

INSTITUTO NACIONAL DE ESTUDOS E PESQUISAS EDUCACIONAIS ANÍSIO TEIXEIRA. Matrículas na rede municipal de educação de Teresina. Disponível em: <http://portal.inep.gov.br/microdados>. Acesso em: 02 mar. 2017.

KNUDSEN, E. et al. Economic, neurobiological, and behavioral perspective son building America's future work force. PNAS, v. 103, n. 27, p. 10155-10162, jul. 2006. Disponível em: <http://www.pnas.org/content/103/27/10155.full.pdf >. Acesso em: 15 nov. 2016.

KUCZYNSKI, P. P.; WILLIAMSON, J. Depois do Consenso de Washington: retomando crescimento e reforma na América Latina. São Paulo: Saraiva, 2003.

LAKATOS, E. M.; MARCONI, M. de A. Téenicas de pesquisa: planejamento e execução de pesquisa, elaboração, análise e interpretação dos dados. 7. ed. São Paulo: Atlas, 2016. 
LIBÂNEO, J. C.; OLIVEIRA, J. F. de; TOSCHI, M. S. Educação escolar: políticas, estrutura e organização. 10. ed. São Paulo: Cortez, 2012.

LUZ, L. X. Participação do empresário na educação no Brasil e na Argentina. Tese (Doutorado em Educação)-Universidade Estadual de Campinas, Faculdade de Educação, Campinas, 2009.

MELLO, G. N. de. Cidadania e competitividade: desafios educacionais do terceiro milênio. São Paulo: Cortez, 1993.

MÉSZÁROS, I. Para além do capital. São Paulo: Boitempo, 2011.

NOTÍCIAS. Semec: Secretaria Municipal de Educação. Disponível em: <http:// www.semec.pi.gov.br/Noticias/Normal/>. Acesso em: 10 dez. 2016.

OBSERVATÓRIO DO PLANO NACIONAL DE EDUCAÇÃO. Acessibilidade educacional. Disponível em: <http://www.observatoriodopne.org.br/metas-pne/10-eja-integrada-a-educacao-profissional/dossie-localidades> Acesso em: 15 fev. 2017.

OFFE, C. Problemas estruturais do Estado Capitalista. Rio de Janeiro: Tempo Brasileiro, 1984.

OLIVEIRA, J. B. A. Reforma da educação: por onde começar? Belo Horizonte: Instituto Alfa e Beto, 2006.

PARTIDO MOVIMENTO DEMOCRÁTICO BRASILEIRO. Uma ponte para o futuro. Brasília, DF: Fundação Ulysses Guimarães PMDB, 2015. Disponível em: $<$ http://pmdb.org.br/wp-content/uploads/2015/10/RELEASE-TEMER_A4-28.10.15-Online.pdf>. Acesso em: 30 jan. 2017.

PEREIRA, L. C. B.; SPINK, P. (Org.). Reforma do Estado e administração pública gerencial. 2. ed. Rio de Janeiro: Fundação Getúlio Vargas, 1997.

PERONI, V. M. V. As relações entre o público e o privado nas políticas educacionais no contexto da terceira via. Currículo sem Fronteiras, v. 13, n. 2, p. 234-255, maio/ ago. 2013.

PERONI, V. M. V.; SILVA, M. V. Estado, Terceira Via, Terceiro Setor e o Instituto Ayrton Senna. In: ADRIÃO, T. M. de F.; PERONI, V. V. M. V. (Org.). Gestão municipal da educação e as parcerias com o Instituto Ayrton Sena. Goiânia: FUNAPE; Recife: ANPAE, 2013. p. 37-59. 
PROGRAMA Alfa e Beto garante alfabetização a alunos de escolas municipais. Semec - Secretaria Municipal de Educação, Teresina, 2013a. Disponível em: <http:// www.semec.pi.gov.br/Normal/Programa-Alfa-e-Beto-garante-alfabetizacao-a-alunos-de-escolas-municipais.html>. Acesso em: 12 dez. 2016.

PROGRAMA Paralapracá será ampliado para todos os Centros Municipais de Educação Infantil de Teresina. Semec - Secretaria Municipal de Educação, Teresina, 2013b. Disponível em: <http://www.semec.pi.gov.br/Normal/programa-paralapraca-sera-ampliado-para-todos-os-centros-municipais-de-educacao-infantil-de-teresina. html>. Acesso em: 17 dez. 2016.

SEMEC analisa resultados da formação de professores. Semec - Secretaria Municipal de Educação, Teresina, 2013a. Disponível em: <http://www.semec.pi.gov.br/ Normal/SEMEC-analisa-resultados-da-formacao-de-professores.html>. Acesso em: 17 dez. 2016.

SEMEC anuncia benefícios para Educação Infantil. Semec - Secretaria Municipal de Educação, Teresina, 2014a. Disponível em: <http://www.semec.pi.gov.br/ Normal/semec-anuncia-beneficios-para-educacao-infantil.html>. Acesso em: 15 dez. 2016.

SEMEC apresenta avanços na educação para outros municípios. Semec - Secretaria Municipal de Educação, Teresina, 2013b. Disponível em: <http://www.semec. pi.gov.br/Normal/SEMEC-apresenta-avancos-na-educacao-para-outros-municipios. html>. Acesso em: 15 dez. 2016.

SEMEC analisa resultados da formação de professores. Semec - Secretaria Municipal de Educação, Teresina, 2013c. Disponível em: < http://www.semec.pi.gov.br/ Normal/SEMEC-analisa-resultados-da-formacao-de-professores.html>. Acesso em: 17 dez. 2016 c.

SEMEC assina convênio com Instituto para discutir com alunos a sustentabilidade. Semec - Secretaria Municipal de Educação, Teresina, 2014b. Disponível em: $<$ http://www.semec.pi.gov.br/Normal/semec-assina-convenio-com-instituto-para-discutir-com-alunos-a-sustentabilidade.html>. Acesso em: $17 \mathrm{dez} .2016 \mathrm{~d}$.

SAÚDE e alimentação. IstoÉ Dinheiro, 2008. Disponível em: $<$ http://www.istoedinheiro.com.br/noticias/economia/20080326/saude-alimentacao/12944>. Acesso em: 18 dez. 2016.

SILVA, J. A. da. Reflexões sobre a história do capitalismo. Revista Filosofia Capital, v. 2, n. 5, p. 102-122, 2007. 
TERESINA é um dos 19 municípios que implementa o projeto "Brincar". Semec Secretaria Municipal de Educação, Teresina, 2013. Disponível em: <http://www. semec.pi.gov.br/Normal/Teresina-e-um-dos-19-municipios-que-implementa-o-projeto-Brincar.html>. Acesso em: 17 dez. 2016.

TERESINA (Município). Extrato de contrato n. 001/2008. Apresenta o acordo entre a Secretaria Municipal de Educação de Teresina-PI e o Instituto Alfa e Beto, tendo em vista aquisição de materiais do Programa Alfa e Beto de alfabetização para o Ensino Fundamental. Diário Oficial Municipal, Teresina, 25 jan. 2008. Disponível em: $<$ http://dom.teresina.pi.gov.br/admin/upload/DOM1199-1-25012008.pdf $>$. Acesso em: 20 maio 2016.

TERESINA (Município). Extrato de contrato n. 001/2011. Apresenta o acordo entre a Secretaria Municipal de Educação de Teresina-PI e o Instituto Alfa e Beto, tendo em vista aquisição de materiais do Programa Alfa e Beto de alfabetização para o Ensino Fundamental. Diário Oficial Municipal, Teresina, 04 fev. 2011. Disponível em: <http://dom.teresina.pi.gov.br/admin/upload/DOM 1383-04022011>. Acesso em: 21 maio 2016.b

TERESINA (Município). Extrato de contrato n. 003/2005. Apresenta o acordo entre a Secretaria Municipal de Educação de Teresina-PI e o Instituto Alfa e Beto, tendo em vista aquisição de materiais do Programa Alfa e Beto de alfabetização para o Ensino Fundamental. Diário Oficial Municipal, Teresina, 28 jan. 2005.

TERESINA (Município). Extrato de contrato n. 003/2012. Apresenta o acordo entre a Secretaria Municipal de Educação de Teresina-PI e o Instituto Alfa e Beto, tendo em vista aquisição de materiais do Programa Alfa e Beto de alfabetização para o Ensino Fundamental. Diário Oficial Municipal, Teresina, 27 jan. 2012. Disponível em: <http://dom.teresina.pi.gov.br/admin/upload/DOM1439-1-27012012.pdf>. Acesso em: 21 maio 2016.

TERESINA (Município). Extrato de contrato n. 008/2010. Apresenta o acordo entre a Secretaria Municipal de Educação de Teresina-PI e o Instituto Alfa e Beto, tendo em vista aquisição de materiais do Programa Alfa e Beto de alfabetização para o Ensino Fundamental. Diário Oficial Municipal, Teresina, 12 fev. 2010. Disponível em: $<$ http://dom.teresina.pi.gov.br/admin/upload/DOM1326-1-12022010.pdf > . Acesso em: 21 maio 2016.

TERESINA (Município). Extrato de contrato n. 011/2004. Apresenta o acordo entre a Secretaria Municipal de Educação de Teresina-PI e o Instituto Alfa e Beto, tendo em vista aquisição de materiais do Programa Alfa e Beto de alfabetização para o Ensino Fundamental. Diário Oficial Municipal, Teresina, 13 fev. 2004. 
TERESINA (Município). Extrato de contrato n. 016/2006. Apresenta o acordo entre a Secretaria Municipal de Educação de Teresina-PI e o Instituto Alfa e Beto, tendo em vista aquisição de materiais do Programa Alfa e Beto de alfabetização para o Ensino Fundamental. Diário Oficial Municipal, Teresina, 24 fev. 2006. Disponível em: $<$ http://dom.teresina.pi.gov.br/admin/upload/DOM1085-1-24022006.pdf $>$. Acesso em: 20 maio 2016.

TERESINA (Município). Extrato de contrato n. 017/2016. Apresenta o acordo entre a Secretaria Municipal de Educação de Teresina-PI e o Instituto Alfa e Beto, tendo em vista aquisição de material didático do programa Alfa e Beto; Prestação de serviços de disponibilização de 1.750 (mil setecentas e cinquenta) licenças de uso do software digital Galáxia Alfa; Aquisição de 280 IAB Testes (Testes Digital). Diário Oficial Municipal, Teresina, 12 fev. 2016a. Disponível em: <http://dom.teresina. pi.gov.br/admin/upload/DOM1867-12022016.pdf>. Acesso em: 22 maio 2016.

TERESINA (Município). Extrato de contrato n. 021/2003. Apresenta o acordo entre a Secretaria Municipal de Educação de Teresina-PI e o Instituto Alfa e Beto, tendo em vista aquisição de materiais do Programa Alfa e Beto de alfabetização para o Ensino Fundamental. Diário Oficial Municipal, Teresina, 14 mar. 2003.

TERESINA (Município). Extrato de contrato n. 021/2013. Apresenta o acordo entre a Secretaria Municipal de Educação de Teresina-PI e o Instituto Alfa e Beto, tendo em vista aquisição de materiais do Instituto Alfa e Beto para utilização didática destinados às escolas da Rede Municipal de Educação. Diário Oficial Municipal, Teresina, 19 jun. 2013a. Disponível em: <http://dom.teresina.pi.gov.br/admin/upload/DOM 1529-19062013>. Acesso em: 21 maio 2016.

TERESINA (Município). Extrato de contrato n. 047/2009. Apresenta o acordo entre a Secretaria Municipal de Educação de Teresina-PI e o Instituto Alfa e Beto, tendo em vista aquisição de materiais do Programa Alfa e Beto de alfabetização para o Ensino Fundamental. Diário Oficial Municipal, Teresina, 06 mar. 2009. Disponível em:<http://dom.teresina.pi.gov.br/admin/upload/DOM1265-1-06032009.pdf>. Acesso em: 21 maio 2016.

TERESINA (Município). Extrato de contrato n. 072/2013. Apresenta o acordo entre a Secretaria Municipal de Educação de Teresina-PI e o Instituto Alfa e Beto, tendo em vista a aquisição de materiais para o Programa de Revisão do $3^{\circ}$ ano e Programa Prova Brasil $5^{\circ}$ ano do Ensino Fundamental. Diário Oficial Municipal, Teresina, 23 ago. 2013b. Disponível em: <http://dom.teresina.pi.gov.br/admin/upload/DOM154823082013.pdf>. Acesso em: 21 maio 2016. 
TERESINA (Município). Extrato de contrato n. 186/2013. Apresenta o acordo entre a Secretaria Municipal de Educação de Teresina-PI e o Instituto Alfa e Beto, tendo em vista aquisição de materiais do Programa Alfa e Beto Pré-escola II para a Educação Infantil, do Programa IAB Prova Brasil $4^{\circ}$ ano, do Programa IAB Prova Brasil $5^{\circ}$ ano e do Programa Intensivo de Alfabetização para os alunos e professores do Ensino Fundamental. Diário Oficial Municipal, Teresina, 10 jan. 2014. Disponível em: $<$ http://dom.teresina.pi.gov.br/admin/upload/DOM1587-10012014.pdf $>$. Acesso em: 22 maio 2016.

TERESINA (Município). Extrato de contrato n. 220/2006. Apresenta o acordo entre a Secretaria Municipal de Educação de Teresina-PI e o Instituto Alfa e Beto, tendo em vista a aquisição dos materiais das unidades I e II que integram o Programa Alfa e Beto de Alfabetização para implementação em 2007 no Ensino Fundamental. Diário Oficial Municipal, Teresina, 12 jan. 2007. Disponível em: <http://dom.teresina. pi.gov.br/admin/upload/DOM1137-1-12012007.pdf>. Acesso em: 20 maio 2016.

TERESINA (Município). Extrato de contrato n. 221/2015. Apresenta o acordo entre a Secretaria Municipal de Educação de Teresina-PI e o Instituto Alfa e Beto, tendo em vista aquisição de 1.000 licenças de uso do software digital Galáxia Alfa. Diário Oficial Municipal, Teresina, 02 set. 2015. Disponível em: $<$ http://dom.teresina. pi.gov.br/admin/upload/DOM1803-02092015.pdf>. Acesso em: 22 maio 2016.

TERESINA (Município). Extrato de contrato n. 473/2016. Apresenta o acordo entre a Secretaria Municipal de Educação de Teresina-PI e o Instituto Alfa e Beto, tendo em vista aquisição de material didático do Programa Alfa e Beto para implementação em 2017 nas etapas Educação Infantil e Ensino Fundamental. Diário Oficial Municipal, Teresina, 26 dez. 2016b. Disponível em: <http://dom.teresina.pi.gov.br/ admin/upload/DOM1996-26122016>. Acesso em: 15 jan. 2016.

TURMAS do programa Alfabetização Solidária concluem atividades de 2007. Semec - Secretaria Municipal de Educação, Teresina, 2013. Disponível em: <http:// www.semec.pi.gov.br/Normal/Turmas-do-programa-Alfabetizacao-Solidaria-concluem-atividades-de-2007.html>. Acesso em: 15 dez. 2016.

Recebido em: 03 de abril de 2017

Aceito em: 06 de junho de 2017

Endereço para correspondência: Campus Universitário Ministro Petrônio Portela, Ininga, 64049-550, Teresina, Piauí, Brasil; cris.anjos.rego@outlook.com 